\title{
A review on Xi Jinping's ideas of ethnic minority work
}

\author{
Shiyuan Hao
}

Received: 26 June 2018 / Accepted: 7 September 2018 / Published online: 25 September 2018 (C) The Author(s). 2018 Open Access This article is distributed under the terms of the Creative Commons Attribution 4.0 International License (http://creativecommons.org/licenses/by/4.0/), which permits unrestricted use, distribution, and reproduction in any medium, provided you give appropriate credit to the original author(s) and the source, provide a link to the Creative Commons license, and indicate if changes were made.

Abstract Ever since the 18th National Congress of the CPC, the Party Central Committee, with General Secretary Xi Jinping at its centre, has focused heavily on ethnic minority work, convening forums on the subject in Tibet and Xinjiang in rapid succession, before ultimately convening a meeting about the general state of the central government's work in this area in 2014. Xi gave several important speeches on topics including the inspection of ethnic minority areas, as well as various speeches made during the talks at the Lianghui (A term referring to the annual plenary sessions of the National People's Congress and the National Committee of the CPC's Political Consultative Conference) about related issues. These speeches did not merely constitute an integral part of Xi's new ideas, (.The citations in this article are from Reference Book on the Spirit of the Central Conference on Ethnic Work, edited by the National Ethnic Affairs Bureau, National Publishing House, 2015; Books of Xi Jinping's Series of Speeches: Creating New Glory of the Chinese Culture, People's Daily, July 9th, 2014; Full Implementation of Party's Ethnic and Religious Policies, Excerpts of Xi Jinping's Speech on the Building of Socialist Politics, Central Party Literature Press, 2017) concepts and strategies for managing state affairs, but also established the guiding principle of ethnic minority work for the Party and the nation in a new historical condition. This article discusses and explores Xi's ideas of ethnic minority work from different viewpoints and methods.

\footnotetext{
S. Hao $(\bowtie)$

Chinese Academy of Social Sciences, N0.5 Jianguomennei Street, Beijing 100732, China

e-mail: liuzhen@ cass.org.cn
} 
Keywords Xi Jinping · Ideas of ethnic minority work · Guiding principle

\author{
Abbreviation \\ CPC: Communist Party of China
}

\title{
Introduction
}

Ethnic minority work is being conducted by the Communist Party of China(CPC) in accordance with Marxist-Leninist nation theory, uniting China's many ethnic minorities and launching a hugely important body of work for both the Party and the nation as a whole. Ever since the 18th National Congress of the CPC, the Party Central Committee, with General Secretary Xi Jinping at its centre, has focused heavily on ethnic minority work, convening forums on the subject in Tibet and Xinjiang in rapid succession, before ultimately convening a meeting about the general state of the central government's work in this area in 2014. Xi gave several important speeches on topics including the inspection of ethnic minority areas, as well as various speeches made during the talks at the Lianghui ${ }^{1}$ about related issues. These speeches did not merely constitute an integral part of Xi's new ideas, ${ }^{2}$ concepts and strategies for managing state affairs, but also established the guiding principle of ethnic minority work for the Party and the nation in a new historical condition. Xi's ideas for ethnic minority work serve as a link between past and future, nurturing past traditions and notions while introducing new ideas. He is drawing deeply on history to set out a broad and all-encompassing vision for a diverse future, integrating Chinese characteristics in the innovation and development of ideas about ethnic minority work. Learning, understanding and implementing Xi's ideas for ethnic minority work require a comprehensive and thorough study of his new political scientific ideas, concepts and strategies. This is because ethnic minority work is not a separate, isolated field; it is an essential part of "socialism with Chinese characteristics' as a whole: "Ethnic minority work involves everything," it is argued, "and everything contains elements of ethnic minority work". This article discusses and explores Xi's ideas of ethnic minority work from different viewpoints and methods.

\footnotetext{
${ }^{1}$ A term referring to the annual plenary sessions of the National People's Congress and the National Committee of the CPC's Political Consultative Conference.

${ }^{2}$ The citations in this article are from Reference Book on the Spirit of the Central Conference on Ethnic Work, edited by the National Ethnic Affairs Bureau, National Publishing House, 2015; Books of Xi Jinping's Series of Speeches: Creating New Glory of the Chinese Culture, People's Daily, July 9th, 2014; Full Implementation of Party's Ethnic and Religious Policies, Excerpts of Xi Jinping's Speech on the Building of Socialist Politics, Central Party Literature Press, 2017.
} 


\section{Discussion}

An in-depth explanation of the theoretical connotations of the correct path for using Chinese characteristics to solve ethnic problems

Most countries across the world possess a certain degree of ethnic and national diversity which commonly leads to some general problems, namely issues of conformity and integration within a society composed of multiple different races, nationalities, religions, languages and individuals. There are numerous, complicated, ways of dealing with these broad, long-term issues, and different countries will act in accordance with different ideas and concepts, choose different paths and design different policies, systems and regulations, all of which lead to wildly divergent outcomes.

Since the 1990s, the vast majority of the world's conflicts have been set against the national and international backgrounds of what may be generally described as ethnic affairs, as manifested in rapid succession by the collapse of the Soviet Union, the Yugoslav wars, American racial conflict and Scotland's bid for independence from the UK, not to mention the immigration issues that are troubling many Western countries or the challenges of so-called 'political correctness' within multiculturalism. Thus, when it seemed that multiculturalism had become a failed experiment across the Western world, inflicting social division, religious extremism and the ravages of terrorism, China realized it had come to a critical juncture: it needed to survey and review systems, ideologies, theories and strategies for solving its own ethnic issues. Under the motto, "The correct path for using Chinese characteristics to solve ethnic affairs," Xi has proposed exploring different paths, systems and theories, as well as drawing on cultural confidence, to establish political stamina and a basic standpoint from which to proceed.

Respecting history is the theoretical foundation for Xi's ideas for ethnic work, and, at the same time, it is the concrete basis for his political-scientific ideological system of using 'Chinese characteristics.' Xi has pointed out that, "When explaining what constitutes Chinese characteristics, we must clearly discuss the differing historical traditions, cultural bases and fundamental national conditions of different nations, nationalities and ethnic groups. Once this is understood, unique characteristics will naturally emerge along the path of development." (Jinping 2014a, 2014b, 2014c, 2014d) Thus, in his speeches, he looked back at how previous dynasties dealt with China's border regions populated with ethnic minorities; political unification was put forward as an essential prerequisite, although different governance systems were used within differing regions, emphasizing the ancient Chinese political precept of 'governing according to local circumstances.' Xi went on to state that, "Maintaining unification while respecting and attaching great importance to social and cultural differences has always been hugely important to the formation and development of the Chinese nation." These are the established, solid historical ideas behind 'Chinese characteristics'; they are mechanisms that have guided China's evolution into a unified, multi-ethnic country.

In keeping with national conditions is a fundamental principle underpinning $\mathrm{Xi}$ 's ideas for ethnic minority work. Xi has insisted that, "The Party must keep in mind that China as a unified, multi-ethnic country is a basic, fundamental national 
condition." This condition has a long tradition, one that has been passed down since the dawn of Chinese civilization and that has some specific characteristics, "creating an eclectic, mixed distribution of ethnic groups across China, incorporating and assimilating a wide range of cultures which were economically dependent on one another, became close-knit on an emotional level and formed the diverse yet whole structure of the Chinese nation, embodying the notion of 'there is a me in you, and there is a you in me, everyone is inseparable." These new ideas are equally based on the 'view of China' within Marxist historical materialism, that China is a united, multicultural nation; this has been a consistent view of the Chinese people. Given the national conditions and unique circumstances China has experienced over the long course of its history, statistics such as the '56 ethnicities,' 'a population of 1.3 billion' and '9.6million square kilometers of land' mentioned in Xi's speech all help to elaborate China's current state. Arguably, on a global scale, no other ruling party is faced with such challenges; thus Xi firmly emphasized that, "If we do not stoutly adhere to the path of socialism with Chinese characteristics, what other mode of governance can we emulate, who else can guide us and tell us what to do?" (Jinping 2014a, 2014b, 2014c, 2014d) .This is also the case when dealing with ethnic affairs using Chinese characteristics, because it must be done in accordance with national conditions which means including the basic desires, interests and common aspirations of China's different ethnic minorities.

Complying with the will of the people is the essence of Xi's thinking about ethnic work. Traditional Chinese culture acknowledged that, in governing the people, "water [i.e. the people] can float the boat [the nation], but equally water can submerge it." The CPC has made maintaining the basic interests of the Chinese people its main purpose, and it is through revolution and the establishment of effective governance that a ruling regime can earn the trust of the people and adhere to their common will. For a unified, multicultural nation, maintaining national unity while acknowledging diversity is a scientific dialectical mode of thought: diversity constitutes the organic whole of the extended family that is the Chinese nation, each ethnic minority being an equal and essential member of this family and everyone being inseparable from everyone else. This extended family respects differences and encompasses a wide range of ideas and concepts, embodied and fine-tuned within the Regional Ethnic Autonomy System, which not only recognizes the scientific truth that different ethnicities will have their own individual characteristics, but also understands the inherent need for complying with the will of the people.

Xi's plans for ethnic minority work are founded on the basic principles of using appropriate system designs, laws and policies, under a general banner of 'Chinese characteristics' and 'a correct path,' and on the historical and current reality of a unified yet multi-ethnic China, continuing the long-term, lofty goals of the previous generation of proletariat revolutionaries. The "eight- perseverances' 3 are the core of ethnic minority work, safeguarding its two 'one hundred-year's goals ${ }^{4}$ "The correct

\footnotetext{
3"Eight perseverances" refer to persevering in the leadership of CPC, the socialist road of Chinese characteristics, the safeguarding of the national unity, the equality between all ethnicities, and perfecting the regional ethnic autonomy system, the common unity, efforts, prosperity and development between all ethnicities, the strengthening of the ideological foundation of a shared community of Chinese nation, the governance of the country by law.
} 
path, using Chinese characteristics to solve ethnic affairs," is the guiding principle, when it is laid out, the details are easy to deal with.

An innovative explanation of the basic viewpoints of ethnic work theory in the new era

When discussing the issue of socialism with Chinese characteristics, Xi emphasized that, "a nation must know itself, it must know where it came from, where it must go, it must think clearly and correctly, and it must stride unwaveringly towards its ultimate goal." (Jinping 2014a, 2014b, 2014c, 2014d) 'Thinking clearly and correctly' is how the CPC intends to approach various ethnic affairs, while adhering to and perfecting the Regional Ethnic Autonomy System is the only option for '[striding] unwaveringly towards its ultimate goal.' All our ethnic national policies stem from and rely on the Regional Ethnic Autonomy System. If this source changes, then the foundations will shake along with it, creating a domino effect regarding the issues of national ethnic theory, policies, relations and so on. This is the most profound theoretical and practical significance of our party's adherence to and efforts to improve the Regional Ethnic Autonomy System, as well as a response to various muddled ideas such as 'abolishment theory,' 'province reform theory,' 'USSR-esque policy' and issues of misattribution.

Not too long ago, many would assert that, “America doesn't have its own national identity or distinguish between its nationalities and ethnicities, therefore America doesn't have a Regional Ethnic Autonomy System, and America has not suffered any kind of national division," to call China's Regional Ethnic Autonomy System into question and mislead public opinion, while heaping praise on the 'American experience.' In response to this, Xi said, "We cannot suddenly import a foreign political system and assume it will work in our country, nor can we see what other countries have that we don't and simply interpret them as our nation's shortcomings; neither can we assume the things we have that other nations don't have are superfluous and must be disposed of. These two concepts are oversimplified, one-sided and lack nuance; they are false notions. (Jinping 2014a, 2014b, 2014c, 2014d) In reality, these are merely conclusions the Chinese people have drawn after witnessing the collapse of the Soviet Union, the Yugoslav wars and various revolutions. When dealing with ethnic affairs, not only do US and other Western nations lack a 'miracle cure,' but they have also fallen inextricably into the mess that is 'political correctness,' frequently proclaimed as a major factor in the 'failure of multiculturalism." By clarifying the source of the issue, utilizing international comparison and making an overall judgment, Xi proposed a series of ideological concepts and notions regarding ethnic work, which are as follows.

Having made an inventory of the nation's basic 'resources,' we must make every effort to understand the individual qualities of each ethnicity and elucidate

\footnotetext{
${ }^{4}$ Two one-hundred-year's goals refer to the realization of the socialist modernization at the centennial anniversary of the founding of CPC, and the realization of a socialist modernization power at the centennial anniversary of the founding of the People's Republic of China.

5“Three kinds of power" refers to ethnic division, religious extremism, violent terror.
} 
the importance of ethnic work. Xi began by highlighting the 'multi-ethnic' state of China, which is considered to be one of its 'greatest characteristics' and one of the 'most beneficial factors' behind China's development, rather than an 'albatross around the nation's neck,' 'a burden' or 'troublesome.' "The nation's diversity is an important treasure," he said, 'passed down to us by our ancestors.' He went on to discuss the previous generation of leaders' view of China as a "vast territory with abundant resources," such as water resources and cultural riches, as well as less favourable factors such as the remoteness of frontier regions and poverty in areas inhabited primarily by ethnic minority groups. He promoted a deeper understanding of China's basic national conditions, emphasizing the importance of ethnic work for both the Party and the nation as a whole, as well as the need to protect and effectively put to use China's 'resources,' while meeting the challenge of difficult and harmful elements. Xi finally emphasized that, although effectively carrying out ethnic work would be a daunting task, its overall importance cannot be overstated.

From the combined perspective of unification and autonomy, $\mathrm{Xi}$ explained that maintaining unity was in the nation's greatest interest and constituted an essential foundation for autonomy. To this end, the Party has brought together various factors - history and reality, politics and economics, ethnic groups and ethnic regions - in order to expound the unique characteristics of this system. Xi further emphasized that without national unity it would be impossible to even begin talks regarding the Regional Ethnic Autonomy System. Unification must be based on realizing autonomy in the context of the specific features of ethnic groups and ethnic regions. The scope of national unification includes factors such as the unity of CPC leaders, and the concept that each of China's Autonomous Regions belongs to everyone in China, regardless of ethnicity, and they should all be governed by the Party, thus ensuring that, when implementing the Regional Ethnic Autonomy System, it will not merely be ethnic minority groups who must undertake the even greater responsibilities of maintaining national unification and uniting with other ethnic groups, but the Party that will also have to resolutely maintain the unity of its leaders.

From the fundamental theory of a superstructure and an economic base, Xi elucidated the need to improve the Regional Ethnic Autonomy System. The superstructure and the expression of its superiority rely on the support of the economic base. Xi has pointed out that, "the key to implementing the Regional Ethnic Autonomy System lies in helping these autonomous regions develop their economy and improve their people's livelihoods." Otherwise, that autonomy would only be an empty promise. "If the disparities in the development of the autonomous regions continue to follow this general trend in the long term, without reaching a radical turning point, this will cause psychological instability, even leading to an imbalance in ethnic and regional relations." Thus, improving people's livelihoods (with an emphasis on employment and education), developing the resource advantage of ethnic regions (centered on benefiting local regions and securing ecological protection), alleviating poverty through development (in destitute areas) and reinforcing the development of border areas (focusing on infrastructure and the opening of those regions to the outside world) have become focal points for the implementation of the 
Regional Ethnic Autonomy System. This starts from the reality of accelerating national development through diversified policies in order to uphold and improve the Regional Ethnic Autonomy System and the necessary process of establishing solid social, welfare and economic bases. At the same time, from the strategic perspective of the comprehensive rule of law, Xi has highlighted the duty to "deepen research on the legislation and systems relevant to the regulation and improvement of Regional Ethnic Autonomy," and "effectively implement the rules of the Constitution and of the Regional Ethnic Autonomy Law."

In terms of the livelihood of the different ethnic minorities, he illustrated how strengthening national unity has strategic, fundamental and long-term values. Since the 18th National Congress of the CPC, General Secretary Xi has mentioned national unity several times: from the vivid 'pomegranate' metaphor to the 'holding hands and helping one another' evaluation, from the conclusion that 'national unity is the cornerstone of development and progress' to the motivating statement that 'the Chinese nation is a family, building the Chinese dream together.' He reiterated the principle of opposing 'dual nationalism' as 'it is the greatest enemy of national unity,' instead promoting the use of the comprehensive rule of law to 'safeguard national unity', and insisted that the promotion of national unity should be integrated into national, cadre and social education. He also indicated the long-term directions that ethnic work should take.

From the perspective of the common destiny of the pluralistic whole that is the Chinese nation, he expounded on the idea that nobody is left behind in this big family. In the current nation-state system, the Western idea of 'one nation, one state' becomes 'the nation is one body, one state' for China. This national whole is the modern body constituted by multiple parts, but also shaped by history. The proposition that 'the Chinese nation is one' means that the whole does not need to be divided into multiple elements. The different parts are needed to build a whole, but they depend on it, because, "The whole is the main line and path, while the parts are the key constituents and forces, and both sides are in a relation of dialectical unity." This is the fundamental principle of Chinese characteristics. In the pluralistic whole of the family of the Chinese nation, each family member lives in equality, solidarity, cooperation and harmony, and nobody is left behind. "The Chinese nation is a community united by destiny, where the honour of one is the honour of all, and an injury to one is an injury to all. Only by tightly linking one's own destiny with the fate of the Chinese nation can each nationality have a promising prospect." Regardless of whether it is about alleviating poverty and establishing a moderately prosperous society or the great rejuvenation of the Chinese nation, the 'key constituents and forces' of the 56 nationalities are all necessary.

When it comes to the profundities of Chinese cultural identity, Xi has elucidated the significance of a shared spiritual homeland. "Chinese culture is the agglomeration of all ethnic cultures." and that equating Chinese culture to Han culture, neglecting the culture of ethnic minorities or separating one's own ethnic culture from Chinese culture at the expense of identifying oneself with Chinese culture are mistaken standpoints and must be discarded. Xi pointed out that it is not right not to allow an ethnic group to identify only with their own ethnic culture, since identifying with Chinese culture and identifying with one's own ethnic culture are not 
mutually exclusive. In the pluralistic whole of the great Chinese family, all family members must first of all know they are part of this family, cultivating their consciousness and fostering their Chinese cultural identity from the earliest age, because the Chinese cultural identity is the deepest level of their identity, the "root of national unity and the spirit of ethnic harmony." It is only these that allow all ethnicities to fight together and achieve general prosperity, constructing a spiritual homeland shared by each and every ethnic group. In this regard, the basis for safeguarding the culturally diverse 'resources' and for promoting and developing the culture of each ethnicity lies in "strengthening the Chinese cultural identity," by extracting its essence, bringing forth the new and weeding out the old. While visiting Inner Mongolia, Xi gave his interpretation of the meaning of "helping one another," pointing out in particular that the significance of "guarding the gates of your house, guarding the frontiers of the motherland, guarding the beautiful spiritual homeland of the Inner Mongolian minority" lies in every ethnicity forming its own spiritual homeland on the basis of culture but also being one of the key components and forces of the shared spiritual motherland.

In the process of urbanization, we must have an understanding of the trends in the interactions, exchanges and mixing between ethnic groups, illustrating the importance of reinforcing ethnic work in cities. During the process of modernization in China, and following large-scale urbanization, the population movements of each ethnicity increased greatly in scope and speed, and the mutual relations between ethnic groups also furthered socialization, interaction and intermingling, which meant that the field of ethnic work was extended to society as a whole. In the new circumstances of growing urbanization in China, "cadres everywhere must study the Party's ethnic theory and ethno-religious policies, because ethno-religious issues can happen anywhere." Especially in the social field of cities, where ethnic populations interact, have exchanges and blend together, it is not possible to implement closed-door or laissez-faire tactics, and even less to group minorities in 'ghettos.' Instead, it is essential to guarantee the legal interests of minorities by valuing, guiding and supervising them, banning discrimination or disguised discrimination in words or actions, and establishing the social structure and environment for mutual embedding, with the objective of "enabling cities to better admit the masses of ethnic minorities, and allowing these masses to better integrate into the cities."

With regard to the strategic construction of the 'The Belt, TheRoad Initiative', $\mathrm{Xi}$ explained that ethnic regions, and especially border areas, bear some responsibility for providing new spaces, in order to expand and support the country's development. The construction of the 'The Belt, The Road' will cause the historical 'fringe' areas and the current western regions, especially areas bordering land routes, to transform into open outposts, connecting areas outside with those inside. This important arrangement is not only "greatly beneficial to ethnic regions, particularly border regions," but also draws from historical experience and from a perspective on the future. This is a very insightful strategic vision which provides an entirely new explanation of the importance of ethnic work for the Party's and the country's overall situation, as well as a profound interpretation of how being a multi-ethnic country is an advantage for national development. 
Starting from the political and policy aspects of ethnic work, Xi has explained that the Party and the people are both important factors in the implementation of ethnic work. The leadership of the CPC is the fundamental guarantor of the success of such work, as history has shown. The Party leadership is not making an empty pledge, because it constitutes a powerful force formed by Party members and cadres of all nationalities from Party organizations at every level. At the frontline of ethnic work, good cadres are not only expected to have strong convictions, serve the people, be diligent, accept responsibilities and be upright and honest, but also to attain a "special level of clarity in discerning between the major issues of right and wrong, of resolution in protecting the actions for national unity and of sincerity in respecting the feelings of each ethnicity." It is important to serve as a bridge and link between ethnic minority cadres and the masses, acting with their fullest confidence and conviction. Cadres of all ethnicities are first and foremost Party members, and not cadres for their own nationality. Cadres working in ethnic regions must learn standard Chinese if they belong to a minority, and are supposed to make their best efforts to learn the minority language if they are Han: this is because "linguistic communication is a major link in interpersonal connections, and if people speak different languages, it is difficult to communicate; if people do not communicate, it is difficult to reach an understanding, and thus it becomes difficult to shape an identity." It is not only an essential condition for the interactions, exchanges and mixing between ethnic groups, but also an important requirement for forming qualified and effective ethnic work cadres.

The above is only a preliminary summary of the basic viewpoints of the nine aspects of ethnic work listed previously, as well as a humble contribution in the form of interpretation and commentary. Still, it is obvious that these basic viewpoints constitute innovative strategic thinking in carrying forward and developing the Party's ethnic theory and ideology, and that they are based on the values of native soil, assertiveness, drawing from both experience and theory, broadening our horizons, having clear intentions, and facing the future with confidence. In order to create a new ideological realm of ethnic theory and ethnic work with Chinese characteristics, it is necessary to conduct serious study and research.

An in-depth exposition of the ideological methods for implementing ethnic work in the new era

Two thousand fourteen was a very particular year for China and the rest of the world with regards to ethnic issues. There are numerous examples. In 2014, the Ferguson unrest in the United States uncovered deep-rooted racial tensions, and made it clear that even if African-American President Barack Obama had been awarded the Nobel Peace Prize, this had not helped society progress towards racial harmony. The end of his presidency was accompanied by division within American society and a severe setback for multiculturalist political correctness. Two thousand fourteen was also the year when the Scottish National Party held a referendum on Scottish independence, andthe movement for the 'self-determination referendum' in the Spanish autonomous community of Catalonia escalated to a critical point, triggering a response of regional nationalist-separatist movements in several 
Western European countries. In the same year, the Crimean independence referendum on the question of returning to within the Russian fold created a 'state within a state' in eastern Ukraine, leading to a civil war, with a background of geopolitical contention between Russia and NATO's eastward expansion. In 2014, a report on human rights released by the Council of Europe showed that discrimination against ethnic minorities existed in 39 European states, and that the notion of the 'failure of multiculturalism' became widespread in Europe, while an atmosphere of populist, xenophobic social mobilization was forming, under the influence of extremist political parties. The 'Islamic State caliphate' rose in the Middle East, occupying territories through acts of radical terrorism and forming the biggest terrorist power in the world today. The list goes on. The effect of these events, together with the refugee crisis in Europe, Brexit, the high frequency of 'terrorist attacks' and social divisions, is challenging the traditional concept of national identity based on nation-states of the Western world, to the point that the 'European people,' who are part of a supra-national union, have also started advocating for a return to the cave in the 'House of Mumbi,' 'building walls,' a 'Muslim ban' and a 'burkini ban.' The Western world, which once proclaimed the 'victory of nationalism over communism' after the collapse of the Soviet Union, is now facing the grave predicament of widespread ethnic issues, accompanied by a resurgence of racism, nationalism and populism.

For China, one of the most important political events in 2014 was the convening of the Central Conference on Ethnic Work. It addressed the 2008 Lhasa violence and the 2009 Urumqi riots and their lasting impact, questioning and reassessing the systems, laws and policies put in place in China after these events to solve ethnic issues. It also touched upon muddled ideas such as 'a hundred-percent USSR-esque' misattribution and inferiority complex, as well as convoking an important meeting on various solutions, such as depoliticization or imitating the 'second-generation ethnic policies' of the American 'melting pot.' During his speech at this conference, Xi pointed out that 65 years after the founding of the New China, the Party's ethnic theory, guidelines and policies have proven to be correct, the method of solving ethnic issues with Chinese characteristics is the correct one, and ethnic relations in China are generally characterized by harmony. Not only did this evaluation give political confidence to Chinese ethnic work, but it also showed the way to an ideological understanding of China, its problems and its ethnic relations. Without such a correct ideological method, it would not be possible to understand the scientific proposition for solving ethnic issues with Chinese characteristics or Xi's ideas on ethnic work.

In order to assess China's current situation, it is necessary to understand the intrinsic logic of the formation and development of a unified multi-ethnic state. Throughout the important series of speeches delivered by Xi Jinping on how to manage state affairs, one of the main themes was his explanation of the historical details of Chinese characteristics, which he did by threading together past and present. In the speech for the opening of the 2014 Central Conference on Ethnic Work, Xi observed that the unified multi-ethnic state was created by the continuous interactions of the 'five ethnicities at the dawn of Chinese civilization' and their descendants, and explained that, in ancient Chinese history, "unity was protected while differences were valued." Adopting the stance of historical materialism, he showed his faith in national 
unification. Only by examining Chinese history through this ideological method is it possible to remove the prejudice, already established in ancient times and persisting until today, that certain dynasties were not part of China.

Comparison with international examples allows us to evaluate with confidence the achievements of ethnic work in China. During the collapse of the USSR, Westerners predicted that all multi-ethnic socialist countries would follow the same fate. More than twenty years later, not only has China, the biggest multi-ethnic socialist state, failed to collapse, but it also is on the road to becoming a world power. One of the main reasons why China did not collapse "is that we have looked for and held on to the correct path for solving ethnic issues, one that was suitable for our county's actual situation." Considering the ideologies and policies adopted by Western countries when dealing with broader ethnic issues, as well as real-world problems, Xi pointed out that the ethnic policies of Western countries are not remotely as good as they claim them to be, and in terms of actually solving ethnic problems, they have no guaranteed success. International, fact-based comparisons are the only way to arrive at an objective differentiation. By contrast, the ideological method of blind accommodation and conscious admiration, which relies on a simplified, one-sided, even false representation to elevate others and belittle and undervalue oneself, to the point of adopting a 'prescription' that changes the country's basic political system, is quite wrong, as well as politically harmful.

In facing new situations and challenges, we must understand the main points of China's ethnic relations and oppose an over-generalizing, binding, ideological method. Following China's modernization, under the influence of several international and domestic factors, the issue of the 'three kinds of power' (Jinping 2014a, 2014b, 2014c, 2014d) continues to lead to relevant regional interactions, giving rise to some new circumstances and challenges. Facing this kind of prominent issue does not mean enlarging its negative influence. This is also because the key to grasping the situation of ethnic work and ethnic relations is to employ an ideological method that is both global and local, both general and specific. In this regard, Xi so adequately affirmed that "the overall situation of China's ethnic relations is good, and the foundation for national unity is stable." On the basis of this realistic appraisal appraisal, he emphasized the potential harm of linking together the issues of an "extremely specific region" or a "small minority of people" and the entirety of the region or of an ethnic group, and especially that it is not possible to link together what happens to members of an ethnic minority with ethnic policies that have been proven to be practically effective for a long time. About these issues, "It is necessary to adduce the facts, discuss the arguments and lead numerous cadres to look at the main viewpoints and at the positive sides of national unity." In practice, the comprehensive and appropriate implementation of ethnic policies relies on popular support, as well as political self-confidence.

In order to promote interactions, exchanges and mixing between ethnic groups, it is necessary to handle differences and commonalities properly. These interactions and exchanges, following modernization, have entered an unprecedented new phase, in which their scale and rate are constantly increasing, and mutual contact between ethnic groups is expanding with each passing day. In these new circumstances, it is doubly important to respect differences and tolerate diversity in order 
to create the social conditions for living, studying, working and enjoying life together. However, in practice, we must acknowledge that mixing does not mean eliminating the differences between nationalities, and even less erasing certain ethnic groups. In promoting the development of interactions, exchanges and mixing, "we cannot have a passive or inert attitude, nor can we be impatient or careless... Many methods, theoretically vague and unsuitable both in theory and in practice, are rooted in not properly grasping the sense of propriety." This propriety lies in the in-depth comprehension of the Party's ethnic theory and policies and in understanding how to be in tune with and fight for people's hearts.

Ethnic relations and issues must continue to be regarded from a political perspective. Not so long ago, depoliticizing ethnic issues in China was a very popular attitude, seemingly suggesting that, as long as one followed the American 'acculturation of ethnic problems,' it was possible to solve these issues. But the reality is very different, because ethnic politics in the United States is not only an organic component of American politics, but also a sign of the 'political correctness' of American multiculturalism. For China, studying ethnic relations on a political level means protecting national unity, opposing ethnic divisions and safeguarding equality between ethnic groups; it does not mean treating all ethnic issues that arise in different social lives as political issues. Xi pointed out that, just as non-ethnic issues should not be treated as ethnic issues, ethnic issues should not be treated as non-ethnic issues. In terms of practice, following Chinese social construction and in the current continuous equalization of public services, certain differentiated measures in ethnic policies automatically lost meaning. At the same time, as some social issues are universal, the types of social issues faced by different ethnic groups are also not classified as ethnic issues. The essence of depoliticization is the de-institutionalization of ethnic regions and the elimination of ethnic policies. On a political level, following the right path of solving ethnic issues with Chinese characteristics is the whole point of "stopping the statement which is in favor of eliminating the Regional Ethnic Autonomy System."

We need to think about the material aspects of ethnic work, and, particularly, about people. At the end of the day, ethnic work is human work. National unity requires the common development of each ethnic group, the material basis of shared growth, and recognizes that 'popular feeling is the most important form of politics,' and the spiritual impulse of 'striving for people's hearts and minds' is the most useful impetus in ethnic work. In ethnic work practice, the "two keys of material force and spiritual force are both to be made good use of," with a view to respecting differences and reducing disparities in China. Respecting differences is part of cultural diversity with a spiritual focus, valuing the individual cultural identity of each ethnicity while promoting a Chinese cultural identity, building the shared spiritual homeland of the Chinese people; on the other hand, reducing disparities is part of socio-economic development with a material focus, such that the success of all nationalities in developing, thriving, reforming and opening up together, constructs the shared material homeland of the Chinese people.

We need to be innovative while implementing ethnic work, but it is necessary to have a grounding in reality, a reality that is rooted in China's actual conditions. We must respect national conditions and traditions, without rejecting new ideas, because our practices are succeeding; we must borrow and learn from the experiences of other 
countries, without blindly copying them; it is especially important to avoid over-simplification, one-sidedness and indecisiveness. We must be aware that many problems do not arise because there are no policies, but because the policies are not put into practice. Therefore, in order for ethnic work to be innovative, it needs to be meticulously designed to the highest quality and painstakingly planned.

\section{Conclusion}

In conclusion, Xi Jinping's ideas on ethnic work have crystallized into a complete picture of theoretical and logical relations, points of view and ideological methods, forming an organic component of his ideology on managing state affairs, while also merging with his ideas about internal affairs, and even foreign affairs. For example, in formulating the vision and operations of 'The Belt, The Road Innitiative' the fundamental concepts of Chinese ethnic policies (respecting differences, reducing disparities) promote common development and prosperity, as well as the social foundations for an interconnection of popular sentiments, national relations of "amity, sincerity, benevolence and tolerance," the notion of humanity as being united by a common destiny; and they embody the promise of "opposing all discrimination and prejudice against specific ethnicities and religions" (Jinping 2014a, $2014 b, 2014 c, 2014 d$ ) and represent the axiom of 'foreign affairs as the extension of internal affairs.' Thus, studying and researching Xi Jinping's ideas on ethnic work can undoubtedly contribute to an in-depth understanding of the ideological connotation of the overall situation of both China and the rest of the world.

\section{Funding}

There is no funding for this study.

\section{Availability of data and materials}

Please contact author for data requests.

\section{Ethics approval}

This research paper is in accordance with the research ethical principles. I have gathered the necessary information officially and legally through related publication. Therefore, I want to approve that there is no mistake concerning the necessary ethical consideration.

\section{Consent for publication}

Not applicable. 


\section{Competing interests}

The authors declare that they have no competing interests.

\section{Publisher's Note}

Springer Nature remains neutral with regard to jurisdictional claims in published maps and institutional affiliations.

\section{References}

Xi Jinping. 2014a. "Better Publicizing the Ideological Work". Xi Jinping: The Governance of China, Foreign Languages Press. p.155.

Xi Jinping. 2014b. "The Youth Should Adopt Consciously the Socialist Core Values". Xi Jinping: The Governance of China, Foreign Languages Press. p.171.

Xi Jinping. 2014c. "Speech at the 60th anniversary of the founding of the National People's congress", People's Daily. Sep.,5th.

Xi Jinping. 2014d. "Promoting the Spirit of 'Silk Road', Deepening the Cooperation between China and Arab". Xi Jinping: The Governance of China, Foreign Languages Press. p.315. 